\title{
Evaluation of Antifungal Activity of Litsea cubeba Plant Extract and Essential Oil against Phytopathogenic Fungi Botryodiplodia theobromae
}

\author{
Pramila Tripathi ${ }^{1}$; A. K. Shukla ${ }^{2}$ \\ ${ }^{1}$ Department of Botany, D.A.V-P.G. College, Kanpur-208001, India \\ ${ }^{2}$ Department of Botany, Indira Gandhi National Tribal University, Amarkantak-484887, India
}

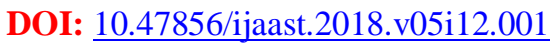

\begin{abstract}
Phytopathogenic fungi Botryodiplodia theobromae causes diseases such as dieback, blights, and root rot in a variety of different hosts in tropical and subtropical regions and it include guava, coconut, papaya and grapevine plants. It also cause stem end rot disease in mango fruits. A number of angiospermic taxa were evaluated for their antifungal activity. Among the selected plants essential oil of L. cubeba was found effective in controlling the growth of Botryodiplodia theobromae. The minimum inhibitory concentration (MIC) of the essential oil was recorded 100ppm. The oil was found to withstand high inoculums density. Plant extract were prepared in water, acetone, ethyl alcohol, petroleum ether, ethyl acetate and methanol. Plant extracts of Allamanda cathartica, Lawsonia inermis, Prunus persica and L. cubeba showed inhibitory effect on the B. theobromae. However, Leaf extract of $L$ cubeba in all the solvent namely, water, acetone, ethyl alcohol, petroleum ether, ethyl acetate and methanol were found to have antifungal activity. The extract as well as oil of $L$. cubeba was also found fungi toxic against other fruit rotting fungi. An enhancement in the shelf life of mango fruits was recorded under in vivo trial after treating with aqueous extract and essential oil of L. cubeba.
\end{abstract}

Keywords: Postharvest diseases, essential oil, stem end rot disease, plant extract.

\section{Introduction}

Phytopathogenic fungi Botryodiplodia theobromae causes diseases such as dieback, blights, and root rot in a variety of different hosts in tropical and subtropical regions. These include guava, coconut, papaya and grapevine. Botryosphaeria dieback, which is formerly known as bot canker, is characterized by a range of symptoms that affect grapevine in particular. These symptoms affect different areas on the plant and can be used to diagnose this disease along with other factors. In the trunk and cordon of the plant symptoms include cankers coming out of the wounds, wedge shaped lesions when cut in cross sections and dieback. Dieback is characterized as a 'dead arm' and a loss of spur positions. More symptoms include stunted shoots in the spring, delay or lack of growth in the spur positions of the bud burst, bleached canes and necrotic buds. Bud necrosis, bud failure, and the dieback of arms are all a result of the necrosis of the hosts' vascular system. An important disease that causes mango rot is stem rot caused by Botryodiplodia theobromae Pat. (Alam and Nahar 1990) and have been reported as a problem in India (DasGupta and Mandal 1989).

Natural products that work with biology have the ability to replace synthetic fungicides. Exploitation of other natural products, such as flavor compounds (Wilson et al., 1987; Utama et al., 2002; 


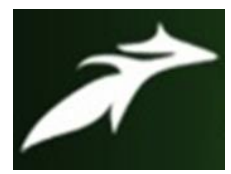

Pramila Tripathi et al, International Journal of Advances in Agricultural Science and Technology, Vol.5 Issue.12, December- 2018, pg. 55-65

ISSN: 2348-1358

Impact Factor: 6.057

NAAS Rating: 3.77

Stadelbecher and Prasad 1974), acetic acid (Chu et al., 2001), jasmonates (Droby et al., 1999), glucosinolates (Mari et al., 2003), essential oils (Tripathi et al., 2004) and extracted plants (Tripathi and Dubey 2003) are well documented. Chemical fungicides provide key ways to control fruit rot after harvest. Continued use of fungicides has been criticized after raising public awareness about the contamination of decaying organisms (fruits and vegetables) with fungicides and their effects as well as increased resistance to pathogen populations. Recently, the exploitation of natural products to control decay and prolong fruit storage life is gaining more attention (Tripathi and Dubey 2004). Keeping all of these factors in mind is an effort made to test certain angiospermic plants as biocontrol against post-harvest fungi of mango fruit.

\section{Material and Methods}

\section{Aqueous extracts preparation, organic solvents extraction and antifungal testing}

Leaves of angiospermic taxa viz., Adhatoda vasica, Allamanda cathartica, Annona squamosa, Callistemon lanceolatus, Catharanthus roseus, Celosia cristata, Clerodendrum indicum, Jatropha gossipifolia, Lawsonia inermis, Leucas aspera, Litsea cubeba, Ocimum canum, Plumeria rubra, Polygonum glabrum, Prunus persica, Rauvolfia serpentina, Solanum nigrum, Tecoma stans and Vitex negundo were screened against $B$. theobromae as well as other fruit rotting fungi. For the preparation of aqueous extract, leaves were crushed with equal amounts (1:1 W/V) of distilled sterile water in grinder. The filtered extract was then used for experiments. The extracts were then assayed for the activity against test fungus by modified paper disc technique (Conner and Beachat, 1984). Ten gram leaves of each plant species were extracted separately in five different organic solvents viz. acetone, ethyl alcohol (absolute alcohol), ethyl acetate, methanol and petroleum ether by macerating them to pulp in a pestle and mortar. The filtrates were assayed separately against the test pathogen by the modified paper disc technique.

\section{Essential oil isolation from the leaves of L. cubeba}

The volatile fungitoxic fraction of leaves was isolated by hydro distillation through Clevenger's apparatus. The isolated fraction showed two distinct layers-an upper oily layer and a lower aqueous layer. Both the layers were separated and the moisture from the oily layer was removed by adding anhydrous sodium sulphate.

\section{Culture of fungi}

The cultures of fungi Botryodiplodia theobromae Pat, Botrytis cinerea Pers ex Fr., Ceratocystis paradoxa (Dade) C. Moreau, Colletotrichum gloeosporioids Penz., Monilinia fructicola( Wint.)Honey, Penicillium digitatum (Pers)Sacc., P. expansum Link ex S.F Gray, P. italicum Wehmer and Phomopsis citri Fawe. were obtained from Indian Agricultural Research Institute, New Delhi. The Cultures of Aspergillus niger Van Tiegh and Rhizopus stolonifer (Ehren. ex FR.) Lind was isolated from the infected mango fruits in laboratory. All the fungal cultures were maintained on PDA medium. The Czepeks agar medium was used throughout the study period. 


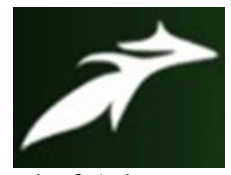

Pramila Tripathi et al, International Journal of Advances in Agricultural Science and Technology,

Vol.5 Issue.12, December- 2018, pg. 55-65

ISSN: 2348-1358

Impact Factor: 6.057

NAAS Rating: 3.77

\section{Antifungal testing and Minimum inhibitory concentration (MIC) of the L. cubeba oil}

Fungitoxicity of the extracted oil was tested by the poisoned food technique (Perrucci et al., 1994). The concentration of the essential oil was prepared by dissolving the requisite amounts in $0.5 \mathrm{ml}$ of $0.1 \%$ Tween-80 and then mixing with $9.5 \mathrm{ml}$ of Czepeks agar medium to produce 500ppm, 400ppm, 300ppm, $200 \mathrm{ppm}, 100 \mathrm{ppm}$ concentrations. The control sets were prepared similarly using equal amounts of sterilized distilled water in place of oil.

\section{Fungitoxicity of the extracts and essential oil of L. cubeba}

The nature of toxicity (fungitoxic / fungicidal ) of the extracts ( leaves extracted in water, acetone, ethyl acetate, ethyl alcohol, methanol and petroleum ether) and essential oil was tested against the test fungus following Thompson (1989).The inhibited fungal discs of the extracts and oil treated sets were reinoculated in to fresh medium and revival of their growth was observed. The range of fungitoxicity of the extracts and essential oil of $L$. cubeba was tested against 10 most common fruit rotting fungi viz. Aspergillus niger, Botrytis cinerea, Ceratocystis paradoxa, Colletotrichum gloeosporioids, Monilinia fructicola, Penicillium digitatum, P.expensum, P.italicum, Phomopsis citri and Rhizopus stolonifer by poison food technique.

\section{Storage effect on fungitoxicity of leaves and oil of L. cubeba}

The effect of increased inoculum densicity of the test fungus on fungitoxicity of the oil was studied following Moleyar and Pattisapu (1987). The effect of storage on the fungitoxicity of leaves of $L$. cubeba was studied by keeping $2 \mathrm{~kg}$ leaves at room temperature $(28 \pm 10 \mathrm{C})$ in a sterilized paper bag for 30 days. The fungitoxicity of the leaves was tested after regular interval of 2 days.

\section{Physicochemical properties of the oil}

The oil was standardized through physicochemical properties viz. specific gravity, specific rotation, refractive index, solubility in different organic solvents, acid number, saponification value, ester value, phenolic content and carbonyl content following Chawdhury and Kapoor (2000).

\section{Comparison of $L$. cubeba oil with some prevalent synthetic fungicides for fungitoxicity}

The efficacy of the oils was compared with some fungicides, viz. benzimidazole(benomyl), diphenylamine, phenylmercuric acetate (ceresan) and zinc dimethyl dithiocarbamete (zirum) by the usual poisoned food technique.

\section{In vivo testing of the extract and oil of $L$. cubeba in control of stem end rot of mango}

Mature healthy fruits of medium size (Dashehari) obtained from local market were used for the experiment. To prepare spore suspension, spores were harvested from 7 day old culture and suspended in sterile distilled water and a wetting agent .01 \% Tween 80. Fruits were wounded and inoculated with $40 \mu \mathrm{l}$ of spore suspension $\left(10^{5} \mathrm{spores} / \mathrm{ml}\right)$ of $B$.theobromae. The inoculated fruits were kept in desiccators. The fruits of treatment sets were given dip treatment in aqueous extract of $L$. cubeba $(1: 1 \mathrm{w} / \mathrm{v})$ for $5 \mathrm{~min}$, 


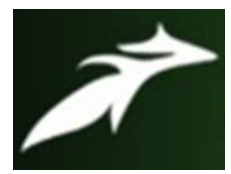

Pramila Tripathi et al, International Journal of Advances in Agricultural Science and Technology,

Vol.5 Issue.12, December- 2018, pg. 55-65

ISSN: 2348-1358

Impact Factor: 6.057

NAAS Rating: 3.77

$15 \mathrm{~min}$ and $30 \mathrm{~min}$. The fruits of control were dipped in water. Five fruits were taken in each control and treatment sets and the experiment was repeated thrice. The observation is based on the mean values.

The in vivo efficacy of oil of L. cubeba was tested by fumigating the inoculated fruits. The inoculation was done by the same method as used with extract. In treatment sets the requisite amount of oil were introduced in desiccators by soaking in a piece of cotton so as to give concentration of $100 \mathrm{ppm}$ $(V / V)$.The initiation of rotting of the fruits was observed. Six replicates were kept for treatment and control sets and the experiment was repeated thrice.

\section{Results}

Plant extract of (water, acetone, ethyl alcohol, ethyl acetate, methanol and petroleum ether) L. cubeba was found to inhibit $100 \%$ mycelial growth of the tested fungus. In comparision to other plants $\mathrm{L}$. cubeba showed more potential antifungal activity and therefore selected for further investigation. With the exception of L. cubeba five other plants namely. Adhatoda vasica (ethyl acetate), Allamanda cathartica (ethyl acetate, methanol), Lawsonia inermis (ethyl acetate), Plumeria rubra (ethyl acetate) and Prunus persica ( ethyl acetate) have also been found to show antifungal activity against pathogen but, their activity was found to be confined to only one or two organic solvents. None of them have been found to be effective in aqueous extract. Ethyl acetate has been found to be a highly desirable solvent in extraction because of these 6 soluble plants they have shown $100 \%$ efficiency. The antifungal activity of these 5 plants was naturally suspended (Table 1 ).

Leaf poisoning persists for 8 days in aqueous extraction while natural solvents are usually up to 25 days for ethyl acetate, 10 days for methanol and alcohol and 5 days for acetone and 2 days for petroleum ether. The sweet smell of the leaves disappeared after the last 5 days. Part of the hot mold was found to be in the form of a pale yellow essential oil with a pleasant, unpleasant odor. The fat content of the plant was $0.5 \%$. The oil completely prevented the growth of mycelial fungus test at 100 ppm showing its MIC at 100 ppm. At 50ppm it inhibited mold growth by 85\% (Table 2).

Toxic substances found static in water, acetone, petroleum ether and whole alcohol, show a weak growth of hyaline mycelial in the medium. However, it was cidal in methanol and ethyl acetate (Table 1). The fungitoxicity of essential oils found to be naturally cidal in the toxic environment (100ppm) and hypertoxic concentrations (200ppm) (Table 2).

Extracts and essential oils of $L$. cubeba show a wide range of fungal toxins that inhibit the growth of all 10 most common fruit rot molds namely; Aspergillus niger, Botrytis cinerea, Ceratocystis paradoxa, Colletotrichum gloeosporioids, Monilinia fructicola, Penicillium digitatum, P.expensum, P.italicum, Phomopsis citri and Rhizopus stolonifer.

It has been noted that oils that inhibit fungal growth of treatment sets contain even 64 discs of the test fungus showing the ability of the oil to withstand the height of the inoculum (Table 2). The oil lasts for up to two years. The oil was naturally warm as it remained toxic to mold at different

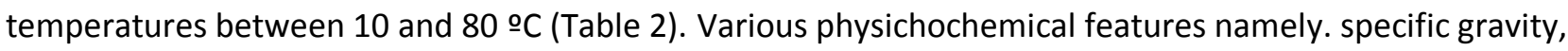




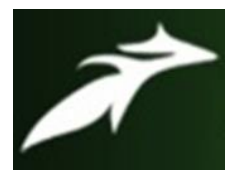

Pramila Tripathi et al, International Journal of Advances in Agricultural Science and Technology,

Vol.5 Issue.12, December- 2018, pg. 55-65

ISSN: 2348-1358

Impact Factor: 6.057

NAAS Rating: 3.77

specific rotation, refractive index, melting of various organic solvents, saponification value, ester value, phenolic content and carbonyl percentage of oil are listed in Table 3.

The MIC of synthetic fungicides benzimidazole, diphenylamine, phenylmercuric acetate and zincdimethyl dithiocarbamate were found to be $200,800,500$ and 400 ppm respectively which was higher compared to L. cubeba oil (100ppm). Hence essential oil was found more potent than synthetic one.

\section{In vivo efficacy of the extract and oil of L. cubeba in control of stem end rot of mango}

The fruits of control sets were completely covered with water soaked brown appearances with ash colored blackish mycelial growth after 6 days of storage showing complete rotting of the fruits. The fruits given 5 min dip treatment did not show any enhancement of shelf life and showed similar symptoms of rotting after 6 days. The initiation of rotting in fruits which were given $15 \mathrm{~min}$ and $30 \mathrm{~min}$. dip treatments in aqueous extract of $L$. cubeba leaves was started after 8 days and 11 days respectively. Therefore the respective enhancement of shelf life was up to 2 days and 5 days in each type of dip treatments (Table 4). The oil treated fruits were found to enhance the shelf life as there was no fungal growth on the treated fruits as compared to control fruits. Though, the initiation of rotting was started after 14 days of storage showing 8 days of enhancement of shelf life but the treated fruits peel showed browning coloration (Table 4).

\section{Discussion}

In the present study extract of L. cubeba in water, acetone, ethyl acetate, ethyl alcohol and methanol have been found to exhibit strong toxicity against $B$. theobromae. Activity was static in water, acetone, whole alcohol and petroleum ether and regenerated mycelium showed weakness with hyaline mycelium. The extracts in ethyl acetate and methanol were found to be cidal as the reconstituted fungal discs were not regenerated when transferred to fresh medium. The efficacy of antifungal activity in water and all organic solvents has shown strong potency of L. cubeba leaf extract which should be used as a potent biocide in controlling phyto pathogen. Recent findings on the effectiveness of essential oils such as biodegradable and ecofriendly fungitoxicants have shown the potential for their exploitation as a natural fungicide (Dixit et al., 1995; Tripathi et al., 2004). The antifungal activity was found in oils of Ocimum, Thymus, Origanum, Anethum, Eucalyptus, Foeniculum and Citrus against several post-harvest germs reveals the marked fungicidal activity of carvacrol (thyme, origanum oil) and p-anisaldehyde ( anethol oxidation products). (Caccioni and Gizzardi 1994). Some volatile aromatic compounds produced by the fruit during ripening also showed antifungal activity. Acetaldehyde has been found to be effective in postharvest protection of apples (Stadelbacher and Prasad 1974) and stone fruits (Caccioni et al., 1994). Hexanal and benzaldehyde, produced by stone fruit metabolism, also have fungistatic / fungicidal activity when used in post-harvest treatment against Monolinia laxa and Rhizopus stolonifer (Caccioni et al., 1995).

In the present study volatile fungitoxic principal was isolated through distillation in the form of essential oils from $L$. cubeba. Yield of oil was $0.5 \%$. The oil was light yellow in color with a strong odor. The oil was 


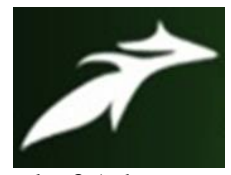

Pramila Tripathi et al, International Journal of Advances in Agricultural Science and Technology, Vol.5 Issue.12, December- 2018, pg. 55-65

ISSN: 2348-1358

Impact Factor: 6.057

NAAS Rating: 3.77

found to be naturally fungitoxic at $100 \mathrm{ppm}$ and hypertoxic at concentrations of $200 \mathrm{ppm}$. The oil was found to be resistant to high inoculum congestion as the oil showed antifungal activity in the treatment sets containing 64 fungal discs. This is another oil potential that should be used as a botanical fumigant. The oil remained toxic for 2 years with a long life span. The oil was able to heat naturally as it was able to withstand temperatures up to $80^{\circ} \mathrm{C}$ without losing toxins. The oil shows high activity at $100 \mathrm{ppm}$ against the 10 most common Indian rotting fungus namely Aspergillus niger, Botrytis cinerea, Ceratocystis paradoxa, Colletotrichum gloeosporioids, Monilinia fructicola, Penicillium digitatum, $P$. expansum, $P$ italicum, Phomopsis citri and Rhizopus stolonifer. Compared with oil MIC and other synthetic fungicides was more effective than suynthetic pesticides as MIC oil was found to be lower (100ppm) compared to synthetic fungicides. The essential oil of $L$. cubeba was found to inhibit the growth of all the phytopathogenig fungi. Si et. al., (2012) reported 59 compounds from L. cubeba oil out of which dominant components were monoterpenes (94.4-98.4\%), represented mainly by neral and geranial (78.7-87.4\%), and D-Limonene was in lesser constituent (0.7-5.3\%). Several components were only detected in certain regions and compounds such as o-cymene and eremophilene have never before been reported in EOLC. Su et. al., (2012) identified main components in oil as $\beta$ - caryophyllene (13.0\%), $\tau$ cadinol (11.1\%), $\alpha$-cadinol (8.6\%), $\alpha$-humulene (7.5\%), $\alpha$-pinene (7.0\%), globulol (6.6\%), and $\beta$-eudesmol (6.1\%). The anti-wood-decay fungal activity of the oil showed that the oil was inhibitory for wood-decayfungi species and compounds were determined to be $\tau$-cadinol, $\alpha$-cadinol, and $\beta$-eudesmol. Yang (2010) through preliminary bioassay study showed $L$. cubeba oil has good fungicidal activities against Sclerotinia sclerotiorum, Thanatephorus cucumeris, Pseudocercospora musae and Colletotrichum gloeosporioides at the concentration of 588 and $272 \mu \mathrm{M}$, and the essential oil has good fungicidal activities against $T$. cucumeris and S. sclerotiorum, with $\mathrm{IC}_{50}$ values of 115.58 and $151.25 \mu \mathrm{g} / \mathrm{mL}$, repectively.

Several fungitoxicants of plant origin have been found to be harmless in treated products and some have shown improvement in their health. In current research extracts and essential oils have proven the good function of the mold by improving the shelf life of mangoes during storage. The fruit was given dip treatment in aqueous leaf extract ( $1: 1 \mathrm{w} / \mathrm{v})$. This treatment for $15 \mathrm{~min}$ enhanced the shelf life up to 2 days, while the dipping of fruits for $30 \mathrm{~min}$ enhanced the shelf life up to 5 days. The oils were used as fumigants at $100 \mathrm{ppm}$ (MIC). The fumigated fruits of treatment sets showed enhanced shelf life up to 8 days. The aqueous extracts did not show any adverse symptoms on the fruit peel. Though the essential oils enhanced the shelf life of fruits but the color of the fruits was turned to brown.

Therefore, the use of these substances as antimicrobial agents can be an interesting field of investigation as the toxicity of mammals is very low, and their flexibility allows them to be used in cold or active packaging. Exfoliation of L. cubeba with strong fungal toxins, moldastatic (in water, petroleum ether and acetone) and fungal environment (in ethyl acetate and methanol), long shelf life and a broad spectrum of fungus may be recommended as a botanical fungi toxicant. More essential oils with low toxicity MIC compared to synthetic, an antiseptic environment against experimental fungi and other decaying fruit fungi, an environmentally friendly environment and effective inoculation resistance is an important fungitoxicant of the L. cubeba. It has the potential to be used as botanical fungicidal fumigant. 


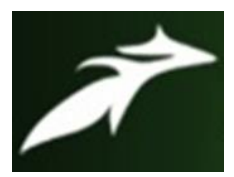

Pramila Tripathi et al, International Journal of Advances in Agricultural Science and Technology,

Vol.5 Issue.12, December- 2018, pg. 55-65

ISSN: 2348-1358

Impact Factor: 6.057

NAAS Rating: 3.77

In vivo experiments with oils have shown a negative effect in the form of brown on the peel of fruit. Similar damage to citrus fruits treated with thyme and cinnamon and essential oils has been reported by Plaza et al., (2004). Therefore the potential use of essential oils to control postharvest diseases requires a detailed examination of their biological activity and dispersion in fruit tissues, and the development of a formula which inhibits the growth of pathogens at nonphytotoxic concentrations. Investigation on the mode of action and practical applicability of such plant products is still required so as to recommend their formulation in control of postharvest diseases.

\section{Acknowledgements}

The authors are grateful to the IARI New Delhi for providing fungal cultures.

\section{References}

[1] Alam MS, and Nahar S. (1990). Post fungal infection changes in L-ascorbic acid content of Mango fruit. Bangla Journal of Botany 19: 2233-225.

[2] Caccioni DRL and Guizzardi M. (1994). Inhibition of germination and growth of fruit and vegetable postharvest pathogenic fungi by essential oil components. Journal of Essential oil Research 6: 173-179.

[3] Caccioni DRL, Tonini G and Guizzardi M. (1994). Postharvest treatments with acetaldehyde vapors for Monilinia laxa (Aderh. And Ruhl.) Honey control in stone fruits', in Proceedings of the Environmental Biotic Factors in Integrated Plant Diseases Control', Poznan, Poland, pp.185-187.

[4] Caccioni DRL, Tonini G, and Guizzardi, M. (1995). Antifungal activity of stone fruit aroma compounds against Monilinia laxa (Aderh. And Ruhl.) Honey and Rhizopus stolonifer (Ehrenb).: In vivo trials. Journal of Plant Disease Protection 102: 518-525.

[5] Chowdhury RA, and Kapoor VP. (2000). Essential oil from fruit of Apium graveolens. Journal of Medicinal and Aromatic Plant Sciences 22: 621-623.

[6] Chu CL, Liu WT, and Zhou T. (2001). Fumigation of sweet cherries with thymol and acetic acid to reduce post harvest brown rot and blue mold. Fruits 56: 123-130.

[7] Conner DE, and Beachat LR. (1984). Effect of essential oils from plants on growth of food spoilage by yeasts. Journal of Food Science 49: 429-434.

[8] DasGupta MK, Mandal NC .(1989). Postharvest pathology of perishables. Oxford and IBH Pub. Pvt, Ltd., UK.

[9] Dixit SN, Chandra H, Tiwari R, and Dixit V. (1995). Development of Botanical fungicide against blue mold of mandarins. Journal of Stored Produced Research 31: 165-172.

[10] Droby S, Porat R, Cohen L, Weiss B, Shapira B, Philosoph-Hadas S and Meir S. (1999). Suppressing green mold decay in grape fruit with postharvest jasmonates application. Journal of American Society for Horticultural Science 124: 184-188.

[11] Mari M, Bertoli P, and Prateiia GC. (2003). Non conventional methods for the control of post harvest pear diseases. Journal of Applied Microbiology 94:761-766.

[12] Moleyar V and Pattisapu N. (1987). Detoxification of essential oil components (Citral and Menthol) by Aspergillus niger and Rhyzopus stolonifer. Journal of Science of Food and Agriculture 39: 239-247. 


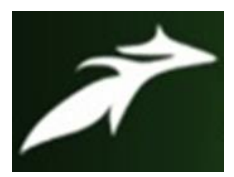

Pramila Tripathi et al, International Journal of Advances in Agricultural Science and Technology, Vol.5 Issue.12, December- 2018, pg. 55-65

ISSN: 2348-1358

Impact Factor: 6.057

NAAS Rating: 3.77

[13] Perrucci S, Mancianti F, Ciont PL, Flamini G, Morelli I and Macchioni G. (1994). In vitro antifungal activity of essential oils against some isolates of Microspermum canis and M. gypseum. Planta Medica 60: 184187.

[14] Plaza P, Torres R, Vsall J, Lamara N and Vinsa IC. (2004). Evaluation of the potential of commercial postharvest application of essential oils to control citrus decay. The journal of Horticultural Science and Biotechnology. 76: 935-940.

[15] Si, L., Chen, Y., Han, X., Zhan, Z., Tian, S., Cui, Q. and Wang, Y. (2012) Chemical composition of essential oils of Litsea cubeba harvested from its distribution areas in China. Molecules, 17, 7057-7066.

[16] Stadelbecher GJ and Prasad K. (1974). Postharvest decay control of apple by acetaldehyde vapour. Journal of American Society of Horticultural Science 99: 364-368.

[17] Su, Y.C., Ho, C.L. (2012) Composition and two activities of the leaf essential oil of Litsea acuminata (blume) kurata from Taiwan. Rec. Nat. Prod., 7, 27-34.

[18] Thompson DP. (1989). Fungitoxic activity of essential oil components on food storage fungi. Mycologia 81: 151-153.

[19] Tripathi P and Dubey NK. (2003). Evaluation of some plant extracts in the management of blue mould rot of mandarin oranges. Indian Phytopathology 56: 481-483.

[20] Tripathi P and Dubey NK. (2004). Exploitation of Natural products as alternative strategy to control post harvest fungal rotting of fruits and vegetables. Postharvest Biology and Technology 32: 235-245.

[21] Tripathi P, Dubey NK, Banergi R and Chansuria JPN. (2004). Evaluation of some essential oils as botanical fungitoxicants in management of post harvest rotting of citrus fruits. World journal of Microbiology and Biotechnology 20: 317-321.

[22] Utama IMS, Wills RBH, Ben-Ye-Hoshua S and Kuek C. (2002). In vitro efficacy of plant volatiles for inhibiting the growth of fruits and vegetable decay microorganisms. Journal of Agricultural Food Chemistry 50: 6371-6377.

[23] Wilson CL, Franlin JD and Otto BE. (1987). Fruit volatiles inhibitory to Monilinia fructicola and Botrytis cinerea. Plant Diseases 71: 316-319. 


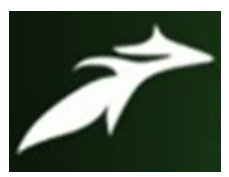

Pramila Tripathi et al, International Journal of Advances in Agricultural Science and Technology,

Vol.5 Issue.12, December- 2018, pg. 55-65

ISSN: 2348-1358

Impact Factor: 6.057

NAAS Rating: 3.77

Table 1. Antifungal activity test for different angiospermic taxa against B. theobromae

\begin{tabular}{|c|c|c|c|c|c|c|}
\hline \multirow[t]{2}{*}{ Angiospermic Plants } & \multicolumn{6}{|c|}{ Solvents used } \\
\hline & Water & Acetone & $\begin{array}{l}\text { Ethyl } \\
\text { acetate }\end{array}$ & $\begin{array}{l}\text { Ethyl } \\
\text { alcohol }\end{array}$ & Methanol & $\begin{array}{l}\text { Petrolium } \\
\text { ether }\end{array}$ \\
\hline Adhatoda vasica Nees (Acanthaceae) & 0 & 5.00 & 100 & 12 & 25 & 5 \\
\hline $\begin{array}{l}\text { Allamanda cathartica Linn } \\
\text { (Apocynaceae) }\end{array}$ & 10 & 90 & 100 & 95 & 100 & 15 \\
\hline Annona squamosa Linn(Annonaceae) & 0 & 0 & 0 & 0 & 0 & 0 \\
\hline $\begin{array}{l}\text { Callistemon lanceolatus } \\
\text { Dc(Myrtaceae) }\end{array}$ & 0 & 10 & 60 & 50 & 10 & 5 \\
\hline $\begin{array}{l}\text { Catharanthus roseus Linn G.Don } \\
\text { (Apocynaceae }\end{array}$ & 0 & 0 & 0 & 0 & 0 & 0 \\
\hline $\begin{array}{l}\text { Celosia cristata } \text { Linn } \\
\text { (Amaranthaceae) }\end{array}$ & 0 & 0 & 0 & 10 & 0 & 0 \\
\hline $\begin{array}{l}\text { Clerodendrum indicum (Linn.) } \\
\text { Ktze(Verbenaceae) }\end{array}$ & 0 & 0 & 0 & 0 & 0 & 0 \\
\hline $\begin{array}{l}\text { Jatropha gossipifolia Linn } \\
\text { (Euphorbiaceae) }\end{array}$ & 20 & 25 & 50 & 45 & 55 & 15 \\
\hline Lawsonia inermis Linn.(Lythraceae) & 50 & 70 & 100 & 95 & 80 & 40 \\
\hline $\begin{array}{l}\text { Leucas aspera } \\
\text { (Willd.)Spreng.(Labiateae) }\end{array}$ & 0 & 0 & 0 & 0 & 0 & 0 \\
\hline $\begin{array}{l}\text { Litsea cubeba } \\
\text { (Lauraceae) }\end{array}$ & 100 & 100 & $100 *$ & 100 & $100^{*}$ & 100 \\
\hline $\begin{array}{l}\text { Ocimum canum Sims } \\
\text { (Labiateae) }\end{array}$ & 5 & 24 & 50 & 35 & 30 & 10 \\
\hline Plumeria rubra Linn.(Apocynaceae) & 20 & 50 & 100 & 40 & 50 & 0 \\
\hline $\begin{array}{l}\text { Polygonum glabrum } \\
\text { Willd.(Polygonaceae) }\end{array}$ & 0 & 0 & 0 & 0 & 0 & 0 \\
\hline $\begin{array}{l}\text { Prunus persica }(\mathrm{L} .) \text { Stockes } \\
\text { (Rosaceae) }\end{array}$ & 60 & 30 & 100 & 80 & 90 & 50 \\
\hline $\begin{array}{l}\text { Rauvolfia serpentina } \\
\text { (Linn.Benth.exkurz)(Apocynaceae) }\end{array}$ & 0 & 0 & 0 & 0 & 0 & 0 \\
\hline Solanum nigrum Linn.(Solanaceae) & 0 & 0 & 0 & 0 & 0 & 0 \\
\hline $\begin{array}{l}\text { Tecoma stans (Linn) H.B.e K } \\
\text { (Bignoniaceae) }\end{array}$ & 0 & 0 & 0 & 0 & 0 & 0 \\
\hline $\begin{array}{l}\text { Vitex negundo Linn. } \\
\text { (Verbenaceae) }\end{array}$ & 5 & 0 & 25 & 0 & 0 & 0 \\
\hline
\end{tabular}

*Cidal nature of extracts 


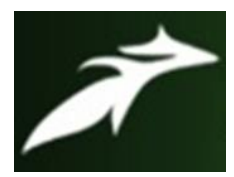

Pramila Tripathi et al, International Journal of Advances in Agricultural Science and Technology,

Vol.5 Issue.12, December- 2018, pg. 55-65

ISSN: 2348-1358

Impact Factor: 6.057

NAAS Rating: 3.77

Table 2.Fungitoxic properties of L. cubeba essential oil

\begin{tabular}{|c|c|c|c|c|c|c|c|c|c|}
\hline \multicolumn{2}{|c|}{ Inhibitory action } & \multicolumn{2}{|c|}{ Fungi toxicity (cidal/static) } & \multicolumn{2}{|c|}{ Inoculums density } & \multicolumn{2}{|c|}{ Thermo stability at one $\mathrm{hr}$} & \multicolumn{2}{|c|}{ Storage effect } \\
\hline $\mathrm{MIC}(\mathrm{ppm})$ & MGI (\%) & $\mathrm{MC}(\mathrm{ppm})$ & MGI (\%) & Fungal discs & MGI (\%) & Temperature $\left({ }^{\circ} \mathrm{C}\right)$ & MGI (\%) & Months & MGI (\%) \\
\hline 50 & 85 & 100 & $100 *$ & 2 & 100 & 10 & 100 & 2 & 100 \\
\hline 100 & 100 & 100 & $100 *$ & 4 & 100 & 20 & 100 & 4 & 100 \\
\hline 200 & 100 & & & 8 & 100 & 30 & 100 & 6 & 100 \\
\hline 300 & 100 & & & 16 & 100 & 40 & 100 & 8 & 100 \\
\hline 400 & 100 & & & 32 & 100 & 50 & 100 & 10 & 100 \\
\hline 500 & 100 & & & 64 & 100 & 60 & 100 & 12 & 100 \\
\hline & & & & & & & 100 & 14 & 100 \\
\hline & & & & & & & 100 & 16 & 100 \\
\hline & & & & & & & 100 & 20 & 100 \\
\hline & & & & & & & 100 & 24 & 100 \\
\hline & & & & & & & & 26 & 50 \\
\hline
\end{tabular}

MIC-Minimum Inhibitory Concentrations; MC-Minimum Concentration; MGI-Mycelial Growth Inhibition; *- Cidal nature

Table 3. Physicochemical properties of the oil extracted from the leaves of $L$. cubeba

\begin{tabular}{lc}
\hline Parameters & Observations \\
\hline Yield of oil & $0.5 \%$ \\
Colour & Light yellow \\
Odour & Pungent \\
Specific gravity at $28^{\circ} \mathrm{C}$ & 0.6832 \\
Specific rotation & $+23.0^{\circ}$ \\
Refractive index & 1.621 \\
& \\
Solubility & \\
Acetone & Soluble $(1: 1$ Conc $)$ \\
Absolute alcohol & Soluble $(1: 1$ Conc $)$ \\
90\% alcohol & Soluble $(1: 1$ Conc $)$ \\
Ethyl acetate & Soluble $(1: 1$ Conc $)$ \\
Benzene & Soluble $(1: 1$ Conc $)$ \\
Chloroform & Soluble $(1: 1$ Conc $)$ \\
Hexane & Soluble $1: 1$ Conc) \\
Methanol & Soluble $(1: 1$ Conc $)$ \\
Acid number & $2.83 m g$ \\
Saponification value & 58.21 mg \\
Ester value & $45.35 m g$ \\
Phenolic content & nil \\
Carbonyl percentage & 2.00 \\
\hline
\end{tabular}


Pramila Tripathi et al, International Journal of Advances in Agricultural Science and Technology,

Vol.5 Issue.12, December- 2018, pg. 55-65

ISSN: 2348-1358

Impact Factor: 6.057

NAAS Rating: 3.77

Table 4. In vivo trial on mango fruits with aqueous extract and essential oil of L. cubeba

\begin{tabular}{|c|c|c|}
\hline $\begin{array}{l}\text { Treatment with aqueous } \\
\text { Extract }(1: 1 \mathrm{~W} / \mathrm{V})\end{array}$ & Initiation of rotting (in days) & Enhancement (in days) \\
\hline Control & 6 & 0 \\
\hline 5 min dipping & 6 & 0 \\
\hline $15 \mathrm{~min}$ dipping & 8 & 2 \\
\hline 30 min dipping & 11 & 5 \\
\hline Essential oil & & \\
\hline Control & 6 & 0 \\
\hline Fumigated at 100ppm & 14 & 8 \\
\hline
\end{tabular}

